\title{
Pengaruh Biochar terhadap Serapan HaraTanaman Jagung Manis pada Tanah Bekas Tambang Batubara
}

\author{
(The Effect of Biochar on Nutrient Uptake of Sweet Corns in \\ Ex-Coal Mining Soil) \\ Riski Rezeki ${ }^{1}$, Yadi Jufri ${ }^{1}$, Syakur ${ }^{1 *}$ \\ ${ }^{1}$ Program Studi Ilmu Tanah, Fakultas Pertanian, Universitas Syiah Kuala \\ corresponding author: syakur@unsyiah.ac.id
}

\begin{abstract}
Abstrak. Biochar adalah bahan organik yang kaya akan kandungan karbon yang dapat dimanfaatkan sebagai bahan pembenah tanah untuk mereklamasi tanah bekas tambang batubara. Biochar dihasilkan dari proses pembakaran bahan organik dalam kondisi oksigen yang terbatas sehingga membentuk pori-pori dan memiliki luas permukaan yang tinggi. Keberadaan pori-pori dan permukaan yang luas pada biochar dapat mengikat air dan memiliki kemampuan dalam mempertahankan nutrisi tanaman. Penelitian ini dilakukan dengan metode Rancangan Acak Kelompok non Faktorial (RAKNF) terdiri dari $\mathrm{A}_{0}$ (kontrol), $\mathrm{A}_{1}$ (biochar cangkang kopi 10 ton ha ${ }^{-1}$ ), $\mathrm{A}_{2}$ (biochar cangkang kopi 20 ton ha ${ }^{-1}$ ), $\mathrm{A}_{3}$ (biochar cangkang sawit 10 ton ha ${ }^{-1}$ ), dan $\mathrm{A}_{4}$ (biochar cangkang sawit 20 ton ha $^{-1}$ ). Perlakuan diulang sebanyak 3 kali. Parameter yang diamati adalah serapan hara N, P, K tanaman. Pengambilan sampel tanaman untuk analisis serapan hara dilakukan pada umur 45 hari setelah tanam (HST). Hasil penelitian diperoleh bahwa pemberian biochar dapat meningkatkan serapan hara N, P, K tanaman jagung manis dan perlakuan biochar cangkang sawit 10 ton ha ${ }^{-1}$ memberikan respon tertinggi terhadap serapan hara tanaman jagung manis.
\end{abstract}

Kata Kunci: biochar, tanah bekas tambang, serapan hara

\begin{abstract}
Biochar is an organic material that is rich in carbon content which can be used as a soil amendment to reclaim land from ex-coal mining. Biochar is produced from the combustion process of organic materials under limited oxygen conditions so that it forms pores and has a high surface area. The presence of pores and a wide surface in biochar can bind water and has the ability to retain plant nutrients. This research was conducted using a non-factorial randomized block design. The treatments consisted of A0 (control), A1 (10 ton ha ${ }^{-1}$ coffee shell biochar), A2 (20 ton ha ${ }^{-1}$ coffee shell biochar), A3 (10 ton ha ${ }^{-1}$ palm kernel shell biochar), and A4 (20 ton ha ${ }^{-1}$ palm kernel shell biochar). The treatments was repeated three times. The parameters observed were N, P, K of sweet corns. Plant sampling for nutrient uptake analysis was carried out at the age of 45 days after planting (DAP). The research prove that by given biochar can increase nutrient uptake N, P, K of sweet corns and the dosage of 10 ton ha ${ }^{-1}$ oil palm shell biochar treatment gave provided the highest response to nutrient uptake of sweet corn.
\end{abstract}

Keyword: biochar, ex-coal mining soil, nutrient uptake

\section{PENDAHULUAN}

Di Indonesia sektor pertambangan merupakan suatu kegiatan yang dinyatakan dapat menggerakkan perekonomian nasional, disebabkan kontribusi pertambangan yang digunakan untuk pembangunan regional cukup besar, dan pertambangan mempunyai optimalisasi penggunaan lahan yang cukup menarik sehingga mampu menambah lapangan pekerjaan, serta dapat memenuhi kebutuhan dalam negeri. Namun dampak yang diberikan akibat aktivitas penambangan batubara menyebabkan ketidakseimbangan ekologi atau ekosistem, sehingga terjadinya kerusakan pada lingkungan, vegetasi sulit tumbuh, dan lahan menjadi tidak produktif. Pada saat terjadi hujan, maka air akan sulit meresap ke dalam tanah atau sebagian besar akan mengalir di permukaan tanah, hal ini mengakibatkan air tanah menjadi berkurang dan berdampak pada erosi yang terus meningkat bahkan banjir hingga longsor akan menjadi 
ancaman terbesar di sekitar tersebut. Mengacu pada berbagai bentuk perubahan yang timbul tersebut maka perlu dilakukan upaya pembenahan tanah dengan menggunakan biochar.

Biochar adalah arang yang diberikan terhadap tanah dan tanaman untuk membenah tanah. Pembuatan biochar melalui proses yang hampir sama dengan arang pada umumnya yang sebagian besar digunakan untuk bahan bakar. Proses pirolisis atau pembakaran bahan organik dalam kondisi oksigen yang terbatas dapat menghasilkan biochar. Namun bahan organik berbeda dengan biochar, dikarenakan biochar merupakan susunan dari cincin karbon aromatis. Hal ini yang membuat biochar lebih stabil dan tahan lama di dalam tanah (Maguire dan Aglevor, 2010). Sebagai bahan pembenah tanah, biochar dapat dipakai dalam mengatasi permasalahan pada tanah dan banyak digunakan sebagai pembenah tanah. Biochar biasanya bermanfaat dalam menaikkan pH tanah (Solaiman dan Anawar, 2015), dan menyediakan unsur hara nitrogen, fosfor, dan kalium (Schnell et al., 2011).

Biochar apabila dimanfaatkan sebagai pembenah tanah dalam bidang pertanian memiliki kemampuan untuk meningkatkan ketersediaan hara bagi tanaman (Gani, 2009). Hal ini karena biochar menurut Steiner et al. (2007) memiliki sifat rekalsitran yaitu lebih tahan terhadap oksidasi dan lebih stabil di dalam tanah apabila diaplikasikan untuk jangka waktu yang lama sehingga memiliki pengaruh jangka panjang pula terhadap perbaikan kesuburan tanah. Biochar juga dapat menyimpan karbon di dalam tanah. Pengkayaan karbon di dalam tanah melalui penambahan biochar memberikan perngaruh baik untuk memulihkan sifat tanah. Dalam hal ini hasil limbah pertanian menjadi daya tarik untuk dimanfaatkan sebagai bahan pembenah tanah yakni sebagai bahan baku biochar. Salah satu limbah pertanian yang dapat dimanfaatkan yaitu cangkang kopi dan cangkang sawit.

Tanaman jagung manis sejauh ini telah banyak dijadikan sebagai tanaman indikator dalam beberapa penelitian yang dilakukan. Hal ini karena tanaman jagung manis merupakan tanaman yang sangat responsif terhadap berbagai perubahan kondisi lingkungan terutama tanah. maka pengaruh pemberian biochar sebagai pembenah tanah terhadap perbaikan sifat kimia tanah pada lahan bekas tambang batubara dapat dilihat dari serapan hara pada tanaman indikator yaitu tanaman jagung manis.

\section{METODE PENELITIAN}

Penelitian dilaksanakan pada bulan Juni 2019 dan Lokasi penelitian dilakukan di kebun percobaan Fakultas Pertanian Universitas Syiah Kuala. Penelitian menggunakan Rancangan Acak Kelompok (RAK) pola Non FaktorialAlat yang digunakan meliputi drum pembakaran, ayakan, cangkul, meteran dan alat-alat laboratorium lainnya. Bahan yang digunakan dalam penelitian ini adalah bahan tanah bekas tambang batubara dari PT Mifa Bersaudara, biochar cangkang kopi dari limbah penggilingan biji kopi, dan biochar cangkang sawit dari limbah pabrik kelapa sawit.

\section{Tahapan Penelitian}

Penelitian terdiri dari beberapa tahap yaitu:

\section{Persiapan Bahan Tanah}

Bahan tanah bekas tambang batubara diambil di lahan bekas tambang batubara dari PT. Mifa Bersaudara yang terletak di Kabupaten Aceh Barat, Meulaboh. 


\section{Persiapan Biochar dan Media Tanam}

Biochar yang digunakan dari bahan dasar cangkang kopi yaitu kulit biji kopi yang berbentuk serpihan-serpihan kecil dari hasil penggilingan biji kopi pada tahap pengelolaan kopi. Biji kopi yang telah kering digiling kasar menggunakan mesin sehingga pada proses tersebut cangkang kopi terkelupas dan terpisahnya cangkang tersebut dengan biji kopi dan berbentuk serpihan yang digunakan dalam penelitian ini. Sedangkan bahan dasar biochar dari cangkang sawit merupakan bagian keras yang terdapat pada buah kelapa sawit yang melindung kernel atau inti buah kelapa sawit atau disebut dengan lapisan endocarp. Cangkang kopi dan cangkang sawit terlebih dahulu ditimbang sebanyak 5-20 kg, kemudian dimasukkan ke dalam drum pembakaran. Media tanam yang akan digunakan dalam penelitian ini menggunakan media pot dengan ukuran diameter pot $28 \mathrm{~cm}$ dan tinggi pot $37 \mathrm{~cm}$. Tanah dikeringanginkan dan diayak menggunakan ayakan $5 \mathrm{~mm}$ dan dimasukkan ke dalam pot sebanyak $20 \mathrm{~kg}$ tanah dan masing-masing pot diberi label sesuai kode perlakuan.

\section{Aplikasi biochar}

Aplikasi biochar pada media tanam dilakukan 2 minggu sebelum penanaman. Biochar yang diberikan pada setiap pot sesuai dosis perlakuan, kemudian tanah tersebut ditutup dan dibiarkan selama 2 minggu.

\section{Penanaman}

Penanaman benih jagung manis dilakukan setelah inkubasi biochar pada tanah selesai. Pada setiap pot ditanam 2 butir benih jagung manis. Penanaman dilakukan dengan ditugal dengan kedalaman $2-3 \mathrm{~cm}$. Setelah itu saat usia tanaman 7 hari setelah tanam (HST), dilakukan seleksi tanaman yaitu dipilih tanaman terbaik dilihat dari pertumbuhannya dan tanaman satu lagi dimatikan dengan cara dibenamkan kedalam tanah.

\section{Analisis serapan hara $\mathbf{N}, P$ dan $K$}

Analisis serapan hara N, P dan K dilakukan dengan cara mengambil sampel daun tanaman pada saat umur tanaman 45 HST, sampel daun di kering anginkan, kemudian dioven menggunakan oven tanaman pada temperatur $70^{\circ} \mathrm{C}$ selama 48 jam. Sampel daun dihaluskan menggunakan grinder. Sampel dianalisis dengan melihat masing-masing konsentrasi komponen hara $\mathrm{N}$ menggunakan metode Kjeldahl, komponen hara $\mathrm{P}$ dan $\mathrm{K}$ menggunakan metode Pengabuan Basah dengan $\mathrm{HNO}_{3}$ dan $\mathrm{HCIO}_{4}$. Nilai total serapan hara dapat dihitung dengan menggunakan rumus Serapan Hara $(\mathrm{mg} / \mathrm{pot})=$ Kadar hara Tanaman Jagung $(\%) \mathrm{x}$ Bobot Kering Tanaman (mg/tanaman).

\section{HASIL DAN PEMBAHASAN}

\section{Kondisi Kesuburan Tanah Bekas Tambang Batubara}

Kondisi kesuburan tanah pada tanah bekas tambang batubara tersebut tergolong kriteria rendah sampai sangat rendah. Hasil analisis awal tanah bekas tambang batubara di PT. Mifa Bersaudara dapat dilihat pada Tabel 1. 
Tabel 1. Hasil Analisis Karakteristik Kimia dan Fisika Tanah Bekas Tambang Batubara.

\begin{tabular}{clccc}
\hline NO. & \multicolumn{1}{c}{ Parameter } & Satuan & Hasil Analisis & Harkat \\
\hline 1 & pH $\left(\mathrm{H}_{2} \mathrm{O}\right)$ & - & 5,55 & Masam \\
2 & C-organik & $\%$ & 0,17 & Sangat rendah \\
3 & N-total & $\%$ & 0,04 & Sangat rendah \\
4 & P-tersedia & $\mathrm{mg} \mathrm{kg}^{-1}$ & 0,30 & Sangat rendah \\
5 & K-total & $\%$ & 0,66 & Sangat rendah \\
6 & K-dd & $\mathrm{cmol} \mathrm{kg}^{-1}$ & 0,16 & Rendah \\
7 & Al-dd & $\mathrm{cmol} \mathrm{kg}^{-1}$ & 4,40 & Tinggi \\
8 & KTK & $\mathrm{cmol} \mathrm{kg}^{-1}$ & 12,00 & Rendah \\
9 & Tekstur & & & \\
& Pasir & $\%$ & 70 & Lempung Berpasir \\
& Debu & $\%$ & 25 & \\
& Liat & $\%$ & 5 & \\
\hline
\end{tabular}

Tabel 1 memperlihatkan bahwa pada tanah tersebut $\mathrm{pH}$ tergolong masam, terdapat kandungan $\mathrm{Al}$ yang tinggi yaitu $4,40 \mathrm{cmol} \mathrm{kg}^{-1}$. Hal ini dikarenakan adanya pencucian yang berlangsung secara intensif terhadap kation-kation basa sehingga tanah didominasi oleh kation-kation asam yang menyebabkan kandungan hara menjadi rendah (Effendi, 1995). Tingginya $\mathrm{Al}$ memungkinkan menurunnya nilai $\mathrm{pH}$ tanah yang pada akhirnya mengakibatkan tanaman mengalami defisiensi hara unsur hara.

Penurunan dan peningkatan $\mathrm{pH}$ pada tanah sangat erat berkaitan dengan proses dekomposisi bahan organik. Bahan organik yang terdekomposisi dapat meningkatkan aktivitas ion $\mathrm{OH}^{-}$yang berasal dari gugus karboksil $(-\mathrm{COOH})$ dan gugus hidroksil $\left(\mathrm{OH}^{-}\right)$. Ion $\mathrm{OH}^{-}$akan menetralisirkan ion $\mathrm{H}^{+}$yang terdapat pada larutan tanah. Brady dan Weil (2002), memberikan pernyataan bahwa naik turun $\mathrm{pH}$ tanah disebabkan oleh ion $\mathrm{H}$ dan $\mathrm{OH}^{-}$. Bahan organik yang didekomposisi oleh mikroba dapat menghasilkan ion $\mathrm{OH}^{-}$, sehingga dapat menetralisir aktivitas ion $\mathrm{H}^{+}$.

Peningkatan $\mathrm{pH}$ pada tanah tersebut dipengaruhi dari hasil terdekomposisinya bahan organik. Hasil dari bahan organik yang telah mengalami dekomposisi tersebut yaitu asamasam organik, yang terdiri dari asam humat dan asam fulvat. Sebagaimana Tan (1991), menegaskan bahwa asam humat dan asam fulvat melalui hasil dekomposisi bahan organik memiliki peran penting dalam proses reduksi aktivitas aluminium dalam tanah sehingga produksi ion $\mathrm{H}^{+}$akan menurun akibat terhidrolisisnya Al. Menurut Young (1989 dalam Sukmawati 2015), bahwa tanah yang subur merupakan tanah yang mengandung bahan organik paling sedikit $2 \%$. Akan tetapi kandungan bahan organik pada tanah bekas tambang ini tergolong sangat rendah yaitu $0,17 \%$.

Rendahnya bahan organik pada tanah tersebut juga mempengaruhi Kapasitas Tukar Kation (KTK). Kandungan bahan organik yang tersedia dalam jumlah sedikit maka akan mengakibatkan KTK menurun karena hilangnya unsur hara akibat pencucian maupun erosi (Kumalasari et al., 2011). Rendahnya KTK pada tanah tersebut menunjukkan pula rendahnya tingkat kemampuan tanah dalam mengikat unsur hara dan melepaskannya agar diserap oleh akar tanaman. Sebagaimana Hardjowigeno (2007) menyebutkan bahwa KTK merupakan salah satu sifat kimia tanah yang sangat berkaitan dengan ketersediaan hara bagi tanaman dan menjadi indikator terhadap kesuburan tanah. 


\section{Serapan Hara Tanaman Jagung Manis}

Pemberian biochar pada tanah bekas tambang batubara memberikan berpengaruh nyata terhadap serapan hara $\mathrm{N}$ dan $\mathrm{P}$ dan $\mathrm{K}$. Perlakuan biochar cangkang sawit 10 ton ha ${ }^{-1}$ $\left(A_{3}\right)$ rata-rata berpengaruh nyata dibandingkan dengan perlakuan lainnya $\left(A_{0}, A_{1}, A_{2}\right.$ dan $\left.A_{4}\right)$.

Tabel 2. Rata-rata Jumlah Serapan Hara N, P dan K Tanaman Jagung Manis akibat Aplikasi Biochar pada Tanah Bekas Tambang Batubara

\begin{tabular}{|c|c|c|c|}
\hline \multirow{2}{*}{ Perlakuan } & \multicolumn{3}{|c|}{ Jumlah Serapan Hara } \\
\hline & $\mathrm{N}$ & $\mathrm{P}$ & K \\
\hline & \multicolumn{3}{|c|}{.......mg per tanaman...... } \\
\hline $\mathrm{A}_{0}($ Kontrol $)$ & $76,99 \mathrm{ab}$ & $17,44 \mathrm{ab}$ & $70,38 \mathrm{ab}$ \\
\hline $\mathrm{A}_{1}\left(\right.$ Biochar Cangkang Kopi 10 ton $\left.\mathrm{ha}^{-1}\right)$ & $126,31 \mathrm{abc}$ & $19,66 \mathrm{bc}$ & $95,66 \mathrm{ab}$ \\
\hline $\mathrm{A}_{2}\left(\right.$ Biochar Cangkang Kopi 20 ton $\left.\mathrm{ha}^{-1}\right)$ & $49,16 \mathrm{a}$ & $8,82 \mathrm{a}$ & $44,03 \mathrm{a}$ \\
\hline $\mathrm{A}_{3}\left(\right.$ Biochar Cangkang Sawit 10 ton $\left.\mathrm{ha}^{-1}\right)$ & $198,77 \mathrm{c}$ & $27,70 \mathrm{c}$ & $162,59 \mathrm{c}$ \\
\hline $\mathrm{A}_{4}\left(\right.$ Biochar Cangkang Sawit 20 ton ha $\left.{ }^{-1}\right)$ & $126,07 \mathrm{ab}$ & $17,82 \mathrm{ab}$ & $108,80 \mathrm{abc}$ \\
\hline $\mathrm{BNJ}_{0.05}$ & 96,09 & 10,25 & 66,78 \\
\hline
\end{tabular}

Keterangan : Angka yang diikuti dengan huruf yang sama menunjukkan tidak ada pengaruh nyata terhadap serapan hara tanaman pada BNJ 5\% (tabel dibaca secara vertikal).

Tabel 2 menunjukkan bahwa pemberian biochar cangkang sawit 10 ton $\mathrm{ha}^{-1}$ memberikan respon terbaik dan dapat dilihat biochar cangkang sawit mampu menyerap hara lebih banyak dibandingkan dengan biochar cangkang kopi. Meningkatnya jumlah serapan hara oleh biochar cangkang sawit dibandingkan dengan biochar cangkang kopi dapat berkaitan dengan struktur pori dan luas permukaan biochar, dimana menurut Liang et al. (2006), dengan adanya area permukaan yang lebih luas maka biochar memiliki kapasitas menahan air yang cukup tinggi pula.

Kemampuan biochar cangkang sawit dalam menyerap hara dilaporkan oleh Santi dan Geonadi $\left(2010^{\mathrm{b}}\right)$, dalam hasil penelitiannya yang menunjukkan bahwa penambahan biochar cangkang sawit dapat mengurangi pencucian hara, sehingga hara yang telah diserap biochar dapat dimanfaatkan oleh perakaran tanaman jagung secara optimal. Sebagai adsorben biochar yang memiliki pori-pori bila digunakan sebagai pembenah tanah akan menyerap memberikan keuntungan terhadap kesuburan tanah melalui penyerapan unsur hara dan meretensi air di dalam tanah (Gani, 2009).

\section{KESIMPULAN DAN SARAN}

Pemberian biochar dapat meningkatkan serapan hara $\mathrm{N}, \mathrm{P}, \mathrm{K}$ pada tanaman jagung manis dibandingkan dengan tanpa pemberian biochar. Perlakuan biochar cangkang sawit 10 ton $\mathrm{ha}^{-1}$ memberikan serapan $\mathrm{N}, \mathrm{P}$ dan $\mathrm{K}$ tertinggi dibandingkan dengan perlakuan lainnya.

\section{DAFTAR PUSTAKA}

Brady, N. C. dan R. R. Weil. 2002. The Nature and Properties of Soil. Pearson Education. New Jersey. 
Effendi, S. 1995. Ilmu Tanah. PT. Medyana Sarana Perkasa, Jakarta.

Hardjowigeno, S. 2007. Ilmu Tanah. Pusaka Utama, Jakarta.

Gani, A. 2009. Potensi Arang Hayati Biochar Sebagai Komponen Teknologi Perbaikan Produktivitas Lahan Pertanian. Iptek Tanaman Pangan. Balai Besar Penelitian Tanaman Padi.4(1).

Liang, B., J. Lehmann., D. Solomon., J. Kinyangi., J. Grossman., B. O’Neill., J.O. Skjemstad., J. Theis., F.J. Luizao., J. Petersen dan E.G. Neves. 2006. Black carbon increases Cation Exchange Capacity in Soils. Soil Sci. Hal:1719-1730.

Maguire, R. O. dan F. A. Agblevor. 2010. Biochar in Agricultural Systems. College of Agriculture and Life Sciences, Virginia Polytechnic Institute and State University.

Schnell, R.W., D. M. Vietor., T. L. Provin., C. L. Munster., dan S. Capareda. 2011. Capacity of Biochar Application to Maintain Energy Crop Productivity: Soil Chemistry, Sorghum Growth, and Runoff Water Quality Effects. Jurnal of Enviromental Quality.

Solaiman, Z., M. dan H. M. Anawar. 2015. Application of Biochars for Soil Constraints: Challenges and Solution. Pedosphere.25(5).

Steiner, C., Teixeira, W., Lehmann, J., Nehls, T., Vasconcelos de macedo, S., Blum, W., dan Zech, W. 2007. Long term Effect of Manure, Charcoal, and Mineral Fertilizer on Crop Production and Fertility on Higly Weathered Central amazon Upland Soil. Plant and Soil.

Tambunan, S., E. Handayanto dan B. Siswanto.2014. Pengaruh Aplikasi Bahan Organik Segar dan Biochar Terhadap Ketersediaan P Dalam Tanah di Lahan Kering Malang Selatan.Jurnal Tanah dan Sumber daya Lahan. 1(1).

Young, A. 1989.Agroforestry for Soil Conservation.Science and Practice of Agroforestry No.4 ICRAF. Nairobi 